\title{
Mentorship: A Return to Basics
}

\author{
Anthony P. S. Guerrero ${ }^{1}$ • Adam M. Brenner ${ }^{2}$
}

Received: 27 January 2016 / Accepted: 9 February 2016/Published online: 28 March 2016

(C) Academic Psychiatry 2016

For a busy medical educator, mentorship is often eclipsed by the "urgent and important" priorities of rules, competency milestones, and other content-related mandates that we need to teach. Yet we all know-from the time we are born- that relationships are key in teaching and learning new things. Relationships keep us motivated and provide us with role models for what is expected and meaningful personalized feedback about how we are progressing towards these expectations. As sophisticated as our televisions and computers have become in showing humans communicating and in capturing human language, children still need actual humans to learn language. In our specialty, we also know that children with normal global intelligence but a social developmental delay (e.g., autism spectrum disorder) are often delayed in learning language and other skills, but can learn effectively with the right teaching approaches.

Most people who have achieved great things (in both real life and in fiction) are more likely to cite the names of the people (or quasi-people, in the case of fairy tales and science fiction movies) who inspired and mentored them than the names of the competencies that they incrementally achieved. Although milestones are important for ensuring fundamental competency and safety of practice, mentorship is what is needed to maintain inspiration and engagement in learning.

Several examples from the everyday world show where mentorship is important in ensuring that "urgent and important" things get done. Many of the complex tasks in our

Anthony P. S. Guerrero

GuerreroA@dop.hawaii.edu

1 University of Hawai' $i$, Honolulu, HI, USA

2 University of Texas Southwestern Medical Center, Dallas, TX, USA specialty are effectively taught in a mentoring context; one example (and especially important in the diverse state of Hawai' $i$, where the first author is privileged to live) is discussing our own cultural background and how it affects interactions with patients (which program directors may readily recognize as PROF1 4.2 [1]). In the first author's experience, whenever faculty complain to him that certain mature psychiatric skills - such as accurately judging who needs an admission for safety and who does not-are not possible to teach, he often challenges them by asking whether this skill could possibly be any more "un-teachable" than purposefully navigating, without any instruments other than the five senses, across thousands of miles of open ocean to reach isolated islands: a skill learned effectively, after several centuries of its absence in Hawai'i, by a determined Native Hawaiian man from a revered Micronesian mentor [2].

In the training context, constructive feedback (e.g., when competencies are not quite met) is generally much more effectively given and received if there is a baseline relationship that is established and nurtured. Relationships are the foundation - albeit hidden, at times - upon which the rules and rituals of academic psychiatry become meaningful. The challenges we face day-to-day with students, residents, and other supervisees are often rooted in tensions (avoidable or not) in relationships of one variety or another.

Along with helping their mentees achieve great things, mentors can be crucial in helping them learn to work through the inevitable disappointments and setbacks of an academic career. Sometimes, the mentor's guidance takes the form of expressions of confidence and encouragement to persist in the face of adversity. Other times (as some of us know from experience!), the best mentoring can come in the form of "tough love" that helps mentees face difficult truths about the gap between their aspirations and their actual current capabilities. In either case, academic careers rarely progress in a steady, 
uninterrupted ascension, and rejections during the early phases can be particularly jarring and contribute to burnout and to attrition. Mentors can be the difference between resilience and demoralization.

Overall, mentorship is key in ensuring the creativity and innovation needed to meet the complex and monumental challenges of modern academic psychiatry. These challenges include preparing the workforce to serve competently in health care's ever-changing framework; growing the workforce in research, education, and administration; diversifying the workforce; and retaining the workforce.

Several papers in the April 2016 issue address this important topic of mentorship and offer concrete, creative, and costconscious solutions to the important challenge of improving and operationalizing mentorship within our specialty and across the spectrum of training levels.

With a focus on residents, Cohen and Kassam [3] assert and demonstrate - via a formalized competency-based mentorship program that includes a thoughtful pairing with (appropriately incentivized) faculty members, a contract, and a list of discussion topics and themes - that "Mentorship is an excellent method to develop a trainee's skills in the non-medical expert CanMEDS roles." CanMEDS is the Royal College of Physicians and Surgeons of Canada's framework for assessing resident physicians, and the non-medical expert roles are communicator, collaborator, manager, health advocate, scholar, and professional.

With a focus on faculty development in education and educational leadership roles, Sexton et al. [4] introduce practice communities (in the everyday workplace) as the ideal forum for informal, cost-effective faculty development in group settings. They describe the experience of the "Mod Squad" group, tasked primarily with revising curricular modules but also able to develop - with guidance from a selected textbook and from module leaders - in their roles as educational leaders, comfortable with curriculum design, implementation, and evaluation.

With a focus on building and sustaining diversity within the faculty workforce, Ford [5] powerfully describes, from a personal perspective, the value of mentorship for women in academic psychiatry. Ford includes practical information about the how and when and the nuts and bolts of mentorship.

With a focus on recruiting future leaders in academic psychiatry, Wrenn et al. [6] describe a pilot, 1-month medical student elective that includes weekly meetings with a mentor, participation in faculty development sessions, delivery of a teaching session, and completion of a scholarly project.

With a focus on recruiting psychiatric researchers, Kupfer et al. [7] describe a successful mentorship program for trainees pursuing mental health research careers as independent scientists. The program includes a workshop followed by longitudinal individual and peer mentorship, some of which is facilitated electronically.

Finally, with a focus on teaching and mentoring future mentors, Lau et al. [8] report on the effectiveness-measured by a validated scale — of a single, half-day, budget-conscious, yet evidence-based mentor training workshop provided to a multidisciplinary group.

Mentorship and relationships in psychiatric education remain important areas for continued scholarship. And, on a personal note, in reflecting upon their careers, the coauthors of this editorial — both academic psychiatrists - are deeply grateful for inspiration from their mentors, grand-mentors (mentor's mentors, if you will), and all generations above.

\section{Compliance with Ethical Standards}

Disclosures On behalf of all authors, the corresponding author states that there is no conflict of interest.

\section{References}

1. The Accreditation Council for Graduate Medical Education and The American Board of Psychiatry and Neurology. The psychiatry milestone project. 2013. https://www.acgme.org/acgmeweb/Portals/0/ PDFs/Milestones/PsychiatryMilestones.pdf Accessed 1 July 2016

2. Polynesian Voyaging Society. Hawaiian voyaging traditions: Nainoa Thompson. http://pvs.kcc.hawaii.edu/index/founder and teachers/ nainoa_thompson.html Accessed 1 July 2016

3. Cohen J, Kassam A. Mentorship for residents in psychiatry: a competency-based medical education perspective with career counseling tools. Acad Psychiatry. 2014. doi:10.1007/s40596-0140248-y.

4. Sexton JM, Lord JA, Brenner CJ, Curry CE, Shyn SI, Cowley DS. Peer mentoring process for psychiatry curriculum revision: lessons learned from the "mod squad". Acad Psychiatry. 2015. doi:10.1007/ s40596-014-0274-9.

5. Ford J. Mentoring women psychiatry residents: implications for academic leaders and educators. Acad Psychiatry. 2014. doi:10.1007/ s40596-014-0237-1.

6. Wrenn G, Johnson V, Edukuye O, Seawell M. Academic psychiatry elective: mentored academic leadership development for medical students. Acad Psychiatry. 2015. doi:10.1007/s40596-015-0444-4.

7. Kupfer DJ, Schatzberg AF, Dunn LO, Schneider AK, Moore TL, DeRosier M. Career development institute with enhanced mentoring: a revisit. Acad Psychiatry. 2015. doi:10.1007/s40596-015-0362-5.

8. Lau C, Ford J, Van Lieshout RJ, Saperson K, McConnell M, McCabe R. Developing mentoring competency: does a one session training workshop have impact? Acad Psychiatry. 2016 (in press) 